\title{
Compressive Strength of Fly Ash Based Geopolymer Concrete Addition with Fibers
}

\author{
B Anitha Rani ${ }^{1} \mid$ V Bhargavi ${ }^{2}$
}

1PG Scholar, Department of Civil Engineering, Visakha Technical Campus, Andhra Pradesh, India.

${ }^{2}$ Associate Professor, Department of Civil Engineering, Visakha Technical Campus, Andhra Pradesh, India.

To Cite this Article

B Anitha Rani and V Bhargavi, "Compressive Strength of Fly Ash Based Geopolymer Concrete Addition with Fibers", International Journal for Modern Trends in Science and Technology, 6(8): 57-61, 2020.

Article Info

Received on 06-June-2020, Revised on 28-June-2020, Accepted on 25-July-2020, Published on 31-July-2020.

\section{ABSTRACT}

Concrete is the most widely used construction material all over the world. The quantity of the water plays an important role in the preparation of concrete. And the demand of concrete is increasing day by day and cement is used for satisfying the need of development of infrastructure facilities, 1 tonne cement production generates 1 tonne $\mathrm{CO}_{2}$, which adversely affect the environment. In order to reduce the use of OPC and $\mathrm{CO}_{2}$ generation, the new generation concrete has been developed such as Geopolymer concrete (GPC).

Geopolymers are inorganic polymers and their chemical composition is similar to natural materials. Geopolymer binders are the alternatives in the development of acid resistant concrete i.e. durability of concrete. Geopolymer concrete is produced using Fly ash at 100\% replacement to cement and binders like $\mathrm{NaOH}, \mathrm{Na}_{2} \mathrm{SiO}_{3}$ to ignite the geopolymerisation. Many studies were carried out on properties of geopolymer concrete. This study focuses on enhancing the strength of geopolymer concrete by using fibers. $60 \%$ polyester and $40 \%$ polypropylene fibers are added to geopolymer concrete addition with Fly ash content. The trail mixes were casted with addition of fibers at different percentages like $(0.20,0.25,0.30,0.35,0.40,0.45$ and $0.50 \%$ ). Then samples were air-cured for 28 days at ambient temperature. Compressive strength test is conducted on the samples after 3, 7 and 28 days. The optimum value is obtained at $0.40 \%$ addition of fibers when compared to nominal mix(GPC).

KEYWORDS: Geopolymer concrete, Fly ash, $\mathrm{NaOH}, \mathrm{Na}_{2} \mathrm{SiO}_{3}$, Fibers, Compressive strength.

\section{INTRODUCTION}

Concrete occupies a unique position among modern construction materials. It is the only material manufactured at construction sites. It gives considerable freedom to the architect to mould the structural element to any shape or form a freedom that is not possible with other materials. Of course, concrete has limitations it cannot, on its own flow past obstructions and into nooks and crannies. Through compaction, often using vibration is essential for achieving strength and durability of concrete. As concrete is produced and placed at construction sites, under conditions far from ideal, we do often end up with unpleasant results rocks pockets, sand streaks and a host of workmanship related problems. The extensive use of concrete is not only in construction of residential buildings but also silos for many factories Where sometimes chemicals may have to be stored and even the residential buildings are being constructed beside sea, marine structures like deck, bridges etc. 
Geopolymer was the name given by Daidovits in 1978 to materials which are characterized by chains or networks or inorganic molecules. Geopolymer cement concrete is made from utilization of waste materials such as fly ash and ground granulated blast furnace slag (GGBS). Fly ash is the waste product generated from thermal power plant and ground granulate blast furnace slag is generated as waste material in steel plant. Both fly ash and GGBS are processed by appropriate technology and used for concrete works in the form of geopolymer concrete. The use of this concrete helps to reduce the stock of wastes and also reduces carbon emission by reducing Portland cement demand. Alkaline activator solution is a combination of solutions of alkali silicates and hydroxides, besides distilled water. The role of alkaline activator solution is to activate the geopolymeric source materials containing $\mathrm{Si}$ and $\mathrm{Al}$ such as fly ash and GGBS.

\section{LITERATURE REVIEW}

Prakash $\mathbf{R}$ et al.,[1]Studied about the compressive strength of geopolymer concrete. They considered fly ash based geopolymer concrete using alkaline solution. They conducted experimental work by considering 20 geopolymer concrete mixes by evaluating the effect of various parameters affecting compressive strength. Various parameters considered in their study are ratio of alkaline liquid to fly ash, concentration of sodium hydroxide, ratio of sodium silicate to sodium hydroxide, curing time, curing temperature,

dosageofsuperplasticizer, restperiodandadditionalw atercontent.Aftercuring, the tests on specimens for compressive strength at the age of 3 days by different conditions were considered. They observed that as the water cement ratio varies from 0.35 and 0.40 , there is no significant change in compressive strength for 3days. They reported that compressive strength increases in the increase in the curing time, curing temperature, rest period, concentration of alkaline solution and decrease with increase in the ratio of water to geopolymer solids by mass and admixture dosage. The addition of naphthalene based supper plasticizer improves the workability of fresh geopolymer concrete. They concluded that ratio of alkaline liquid to fly ash mass does not affect the compressive strength of the geopolymer concrete compressive strength of the geopolymer concrete decreases with increase in the ratio of water to geopolymer solid mass. With increase in the curing temperature in the range $60^{\circ} \mathrm{C}$ to $90^{\circ} \mathrm{C}$ the compressive strength of the geopolymer concrete also increases.

Vignesh . p et al.,[2] ${ }^{[2]}$ tudied experimental investigation on strength parameters of fly ash based geopolymer concrete with GGBS. In their work they considered fly ash, GGBS and alkaline solutions. They studied strength properties of geopolymer concrete using low calcium fly ash replacing with slag in 5 different percentages, sodium hydroxide of 8 molarity solution was used. After curing they conducted the tests on specimens for compressive strength, split tensile strength and flexural strength test at the ages of 7 days and 28 days. They observed maximum strength was obtained for the replacement of fly ash at $70 \%$ and GGBS at 30\%. They reported that in compressive strength, split tensile strength and flexural strength were decreased beyond the replacement of $30 \%$ of GGBS and $70 \%$ of fly ash.They concluded that the water absorption property of geopolymer concrete achieves $70 \%$ of the compressive strength in first 4 hours of setting.

Madheswaran C.K. et,al., ,[3]In this paper they were investigated about the effect of molarity in geopolymer concrete. Mainly alkaline liquids used for geopolymerisation, i.e. sodium hydroxide and sodium silicate with different $(3,5,7)$ molarities. In this study the influence of ground granulated blast furnace slag on geopolymer concrete. The types of geopolymer concrete mixes are 10\% GGBS and $90 \%$ fly ash, 15\%GGBS and 85\% FA, 20\% GGBS and $80 \% \mathrm{FA}, 50 \%$ GGBS and $50 \%$ of FA. And that mixes were immersed in different concentrations of alkaline activator solutions. The compressive strength of the GPC is increased with the increasing of concentration of $\mathrm{NaOH}$. Higher concentration of sodium hydroxide solution yielded higher compressive strength. The percentages of GGBS varied from 50\%, 75\%, 100\%. It was observed that as percentage of GGBS increases the compressive strength also increases. And the influence of GGBS on strength of geopolymer concrete mixes were studied, it has been observed that the increasing the quantity of GGBS and compressive strength of geopolymer increases. The measured compressive strength of GPC mix is in the range from $45 \mathrm{MPa}$ and maximum of 60MPa for $100 \%$ GGBS. The quantity of GGBS increases and split tensile strength of GPC increases.

Karthik A et,al., [4]The objective of this research was to understand the positiveimpact of 
bio-additives such as terminalia chebula and natural sugars on the durability properties of coal fly ash blast furnace slag based GPC under various chemical attacks. Various tests had been conducted by immersing specimens in $5 \%$ sulfuric acid, $5 \%$ sodium sulfate and $5 \%$ sodiumchloridesolutionfordifferentdurationof7,14, 28,56 and90days to determine the resistance of bio-additives added geopolymer concrete against chemical attacks. After 90 days of immersion, test results confirmed that bio-additives inclusion in coal fly ash blast furnace slag based GPC had undergone weight loss and compressive strength loss in the range of $2.82-3.91 \%, 9.67-12.05 \%$ under sulfuric acid attack, $0.38-0.68 \%$, $2.15-2.95 \%$ under sodium sulfate attack and $0.28-0.51 \%, 0.83-1.33 \%$ under sodium chloride attack was $13.97 \%, 33.57 \%$ under sulfuric acid attack, $1.64 \%, 6.45 \%$, under sodium sulfate attack and $0.86 \%, 2.05 \%$ under sodium chloride attack wasobserved.

Yeonho Park et,al.,[5]This study presents the feasibility of GPC to which crumb rubber from recycled tires has been added. In this research, fly ash, an alkaline liquid mix of sodium hydroxide and sodium silicate, and crumb rubber were used a the basic constituents of GPC. Various factors that influence the compressive strength were studied, such as molarity of sodium hydroxide, size of aggregates, amount of rubber, and types of fly ash. The analysis of variance indicates that fine aggregate can be replaced with an equal volume of crumb rubber, up to $5 \%$ in three types of fly ash based GPC at the 95\% confidence level.

\section{Materials}

\section{EXPERIMENTAL WORK}

\section{Binders}

GGBS is a byproduct of iron industry. GGBS is obtained from quenching molted iron slag from blast furnace in water or steam to produce granular. Then it is dried and granulated in to fine powder. The physical and chemical properties of GGBS used in this investigation is shown in Table 1.

Table 1 Physical properties of GGBS

\begin{tabular}{|c|c|c|c|}
\hline S.No & IS Code & \multirow{2}{*}{$\begin{array}{c}\text { Tests } \\
\text { performed }\end{array}$} & Results \\
\cline { 4 - 4 } & & Specific & GGS \\
\hline 1 & IS $12089: 1987$ & $\begin{array}{c}\text { Spravity } \\
\text { ginen }\end{array}$ & $7 \%$ \\
\hline 2 & IS $12089: 1987$ & Fineness & $7 \%$ \\
\hline
\end{tabular}

Fine aggregate used in this study was locally available river sand of Zone II compliing to IS 383:1970. The specific gravity, water absorption and fineness modulus of fine aggregate used was $2.55,0.806 \%$ and 2.58.Locally procured coarse aggregate from local quarry was used in this investigation. The specific gravity, Bulk density and Water absorption used was $2.9,1738 \mathrm{~kg} / \mathrm{m}^{3}$ (compacted), $1512 \mathrm{~kg} / \mathrm{m}^{3}$ (loosely packed) and $0.502 \%$.

\section{Alkaline activators and Water}

Sodium hydroxide pellets are taken and broke down in distilled water at the rate of required molar concentrations. It is emphatically suggested that the sodium hydroxide arrangement must be readied 24 hours preceding use furthermore in the event that it surpasses 36 hours it end to semi solid fluid state. So the readied arrangement should to be utilized within the time.Water is a key ingredient in the manufacture of concrete. And in this investigation water participates in the chemical reaction with $\mathrm{NaOH}$ pellets. Since it helps to the strength giving binder gel, the quantity and quality of water are required to be looked into very carefully.

\section{Super Plasticizer}

To improve the workability of the silica/RHA based geopolymer concrete, conplast SP 430 super plasticizer which is obtained from FOSROC Constructive Solution Company. And also it served as a high range water reducer. The colour of the conplast is brown liquid and dosage of conplast added as $3 \%$ by weight of binder material.

\section{Fibers}

Polyester and polypropylene fibers procured from Reliance industries private limited were used for this study. Both the fibers were mixed in the ratio of $60: 40$ to give better results.

\section{Fine and Coarse aggregate}


Mix proportion

\begin{tabular}{|c|c|c|c|c|c|c|c|c|c|}
\hline \multicolumn{2}{|c|}{ Ingredients } & $\begin{array}{c}\text { GPC } \\
\left(\mathrm{Kg} / \mathrm{m}^{3}\right)\end{array}$ & $\begin{array}{c}\text { GPC RF } \\
0.20 \\
\left(\mathrm{Kg} / \mathrm{m}^{3}\right)\end{array}$ & $\begin{array}{c}\text { GPC RF } \\
0.25 \\
\left(\mathrm{Kg} / \mathrm{m}^{3}\right)\end{array}$ & $\begin{array}{c}\text { GPC RF } \\
0.30 \\
\left(\mathrm{Kg} / \mathrm{m}^{3}\right)\end{array}$ & $\begin{array}{c}\text { GPC RF } \\
0.35 \\
\left(\mathrm{Kg} / \mathrm{m}^{3}\right)\end{array}$ & $\begin{array}{c}\text { GPC RF } \\
0.40 \\
\left(\mathrm{Kg} / \mathrm{m}^{3}\right)\end{array}$ & $\begin{array}{c}\text { GPC RF } \\
0.45 \\
\left(\mathrm{Kg} / \mathrm{m}^{3}\right)\end{array}$ & $\begin{array}{c}\text { GPC } \\
\text { RF } 0.50 \\
\left(\mathrm{Kg} / \mathrm{m}^{3}\right)\end{array}$ \\
\hline \multicolumn{2}{|c|}{ GGBS } & 394 & 394 & 394 & 394 & 394 & 394 & 394 & 394 \\
\hline \multicolumn{2}{|c|}{ Fibers } & $0 \%$ & $0.20 \%$ & $0.25 \%$ & $0.30 \%$ & $0.35 \%$ & $0.40 \%$ & $0.45 \%$ & $0.50 \%$ \\
\hline \multicolumn{2}{|c|}{ Fine aggregate } & 647 & 647 & 647 & 647 & 647 & 647 & 647 & 647 \\
\hline \multirow{2}{*}{$\begin{array}{r}\text { Coarse } \\
\text { aggregate }\end{array}$} & $20 \mathrm{~mm}$ & 721 & 721 & 721 & 721 & 721 & 721 & 721 & 721 \\
\hline & $10 \mathrm{~mm}$ & 480 & 480 & 480 & 480 & 480 & 480 & 480 & 480 \\
\hline \multicolumn{2}{|c|}{$\mathrm{NaOH}$} & 21.63 & 21.63 & 21.63 & 21.63 & 21.63 & 21.63 & 21.63 & 21.63 \\
\hline \multicolumn{2}{|c|}{ Water } & 23.43 & 23.43 & 23.43 & 23.43 & 23.43 & 23.43 & 23.43 & 23.43 \\
\hline \multicolumn{2}{|c|}{$\mathrm{Na}_{2} \mathrm{SiO}_{3}$} & 112.65 & 112.65 & 112.65 & 112.65 & 112.65 & 112.65 & 112.65 & 112.65 \\
\hline \multicolumn{2}{|c|}{ SP } & 11.83 & 11.83 & 11.83 & 11.83 & 11.83 & 11.83 & 11.83 & 11.83 \\
\hline
\end{tabular}

GPC- Geopolymer concrete

RF - Reliance Fibers

Percentage of replacement in fine aggregate and addition with fibers

\begin{tabular}{|c|c|c|c|c|c|c|c|c|}
\hline \multirow[t]{2}{*}{$\begin{array}{l}\text { Mix } \\
\text { esignation }\end{array}$} & \multirow{2}{*}{ GG } & \multirow{2}{*}{\begin{tabular}{|l|} 
Fine \\
gregate
\end{tabular}} & \multicolumn{2}{|c|}{$\begin{array}{l}\text { Coarse } \\
\text { gregate }\end{array}$} & \multicolumn{4}{|c|}{$\mathrm{NaOH}$ Water $\mathrm{Na}_{2} \mathrm{SiO}_{3} \mathrm{SP}$} \\
\hline & & & $\begin{array}{l}20 \\
\mathrm{~m}\end{array}$ & $\begin{array}{l}10 \\
\mathbf{m}\end{array}$ & & & & \\
\hline $\begin{array}{l}\text { GPC RF } \\
20 \text { S } 0\end{array}$ & 394 & 647 & 721 & 48 & 21.6 & 23.4 & 112.6 & 11.8 \\
\hline $\begin{array}{l}\text { GPC RF } \\
20 \text { S } 25\end{array}$ & 394 & 647 & 721 & 48 & 21.6 & 23.4 & 112.6 & 11.8 \\
\hline $\begin{array}{l}\text { GPC RF } \\
20 \text { S } 50\end{array}$ & 394 & 647 & 721 & 48 & 21.6 & 23.4 & 112.6 & 11.8 \\
\hline $\begin{array}{l}\text { GPC RF } \\
20 \text { S } 75\end{array}$ & 394 & 647 & 721 & 48 & 21.6 & 23.4 & 112.6 & 11.8 \\
\hline $\begin{array}{l}\text { GPC RF } \\
20 \text { S } 100\end{array}$ & 394 & 647 & 721 & 48 & 21.6 & 23.4 & 112.6 & 11.8 \\
\hline
\end{tabular}

\section{Mixing procedure}

Preparation of alkaline solution and preparation of test specimens.

A combination of sodium hydroxide and sodium silicate was chosen as the alkaline liquid. The molarity of $\mathrm{NaOH}$ used for present study was $12 \mathrm{M}$. The ratio of $\mathrm{Na}_{2} \mathrm{SiO}_{3}$ selected was 2.5.Alkaline binder ratio was taken as 0.40 . A solution of $12 \mathrm{M}$ of sodium hydroxide is prepared by dissolving $480 \mathrm{~g}$ of sodium hydroxide pellets in a liter of water. $\mathrm{NaOH}$ solution was prepared one day before casting of specimens and added $\mathrm{Na}_{2} \mathrm{SiO}_{3}$ liquid was added to that solution one hour before casting of specimens.

The GGBS and fine aggregate shall be mixed dry until the mixture is thoroughly blended and is uniform in colour. The coarse aggregate shall then be added and mixed with the GGBS and fine aggregate until the coarse aggregate is uniformly distributed throughout the batch. The alkaline liquid shall then be added and the entire batch mixed until the GPC appears to be homogeneous and has the desired consistency. Mix design were carried out and details are mention in the Table 3.16 .

\section{Test details \\ Compressive Strength Test}

The compressive strength test was carried out using 200 tonnes CTM. Testing procedure followed is as per IS 516:1959 [8].

\section{RESULTS AND DISCUSSIONS \\ Effect of fibers on compressive strength of GGBS based geopolymer concrete}

Table 5 shows the average compressive strength of various GPC mixes tested at 3 days, 7 days and 28 days. Typical mix GPC RF 0.20 denotes geopolymer concrete, RF- Reliance fibers and 0.20 is percentage of fibers. Fig 1 shows the comparative graph of compressive strength of various mix proportions. It is observed that addition of fibers at $0.40 \%$ increases the compressive strength of geopolymer concrete.

Table 5 Average Compressive Strength In MPa of GGBS Based GPC With Addition Of Reliance Fibers

\begin{tabular}{|c|l|l|l|c|}
\hline \multirow{2}{*}{ S.No } & \multirow{2}{*}{$\begin{array}{c}\text { Mix } \\
\text { designation }\end{array}$} & \multicolumn{3}{|c|}{ Compressive strength (MPa) } \\
\cline { 3 - 5 } & 3 days & $\mathbf{7}$ days & $\mathbf{2 8}$ days \\
\hline 1 & GPC & 39.00 & 46.00 & 58.00 \\
\hline 2 & GPC RF 0.20 & 38.33 & 42.67 & 54.00 \\
\hline 3 & GPC RF 0.25 & 36.00 & 43.33 & 55.00 \\
\hline 4 & GPC RF 0.30 & 35.67 & 45.33 & 56.00 \\
\hline 5 & GPC RF 0.35 & 34.00 & 46.67 & 58.00 \\
\hline 6 & GPC RF 0.40 & $\mathbf{4 1 . 3 3}$ & $\mathbf{4 8 . 3 3}$ & $\mathbf{6 1 . 0 0}$ \\
\hline 7 & GPC RF 0.45 & 38.67 & 44.83 & 55.33 \\
\hline 8 & GPC RF 0.50 & 36.00 & 42.33 & 53.00 \\
\hline
\end{tabular}


comparison of compressive strength of cubes with addition of fibers for 3,7 and 28 days

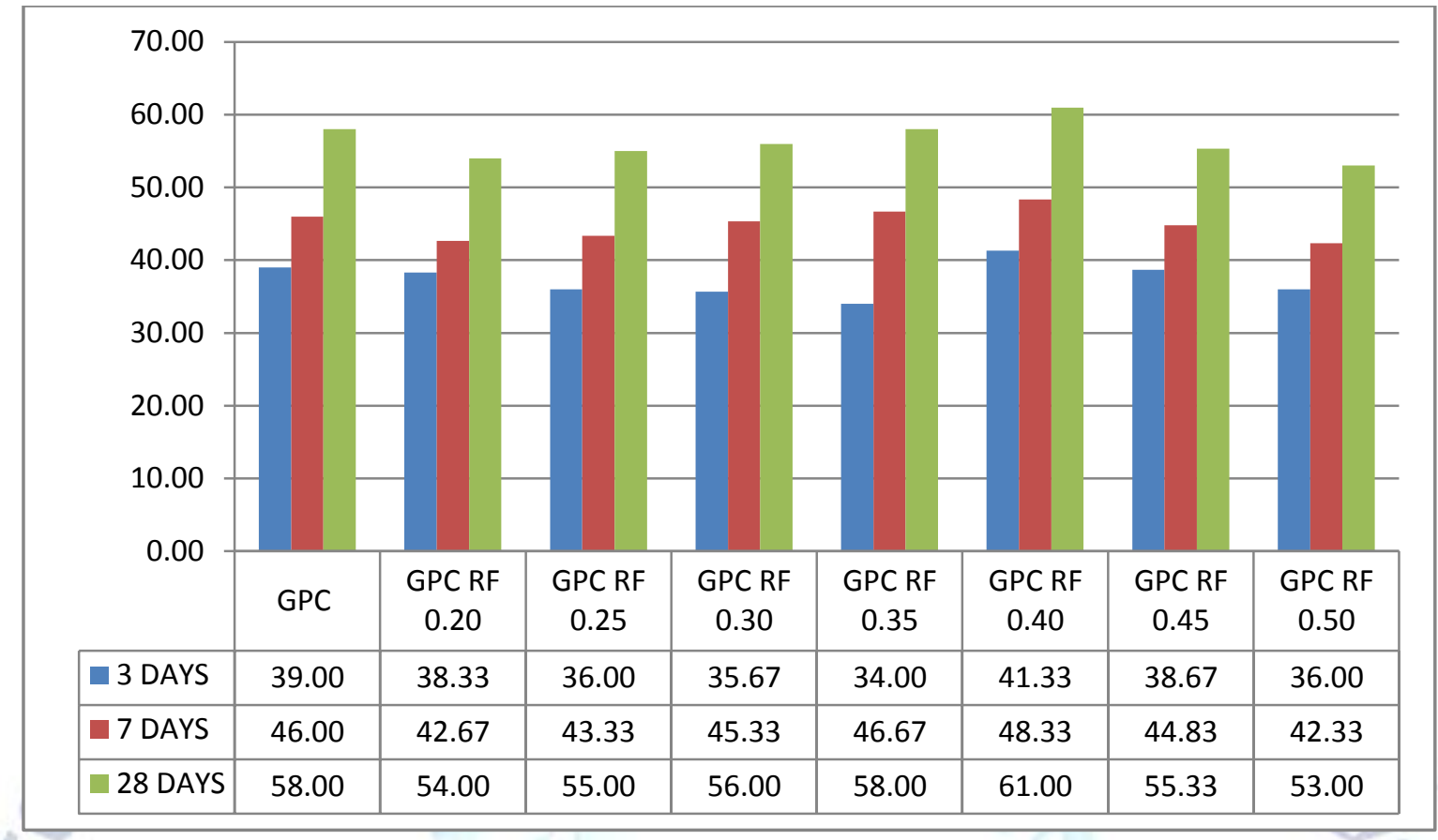

Based on results and discussions following conclusions were made.

> Geopolymer concrete exhibited higher compressive strength when compared to ordinary Portland concrete,

$>$ The optimum percentage of fibers that can be added to geopolymer concrete is at $0.40 \%$.

$>$ Compressive strength decreases with increase of fibers percentage but at $0.40 \%$ addition of fibers the strength has increase than the nominal mix.

\section{REFERENCES}

[1] Madheswaran C. K, Gnanasundar G, Gopalakrishnan.N., Effect of molarity in Geopolymer Concrete, International Journal Of Civil And Structural Engineering, 2013, pp. 106-115.

[2] K. Korniejenko, E. Fraczek, E.Pytlak, M.Adamski., Mechanical properties of Geopolymer Composites Reinforced with Natural fibers, science direct, procedia engineering, 2016, pp. 388-393.

[3] Azizulislam, U.JohnsonAlengaram, MohdZamin Jumaat, Nurasyiqin Binti Ghazali, SumianiYusoff, Iftekhairlbnul Bashar, Influence of steel fibers on the mechanical properties and impact resistance of lightweight geopolymer concrete, Construction and Building Materials, 2017, pp.964-977.

[4] Mahdi Rafieizonooz, Jahangir Mirza, MohdRazman Salim, MohdWaridHussian, Elnaz Khankhaje., investigation of coal bottom ash and fly ash in concrete as replacement for sand and cement, Construction and Building Materials, 2016, pp. 15-24.

[5] IS 10262:1982(Reaffirmed 2004) - Recommended Guidelines For Concrete Mix Design, Bureau of Indian Standard, New Delhi-2004.

[6] IS 2386:1963 (Part I, III)- Methods Of Testing Aggregates For Concrete, Bureau of Indian Standard, New Delhi-2004.
[7] IS 12089:1987 (Reaffirmed 2004): Specification for Ground Granulated Slag for the Manufacture of Port land Slag Cement. Bureau of Indian Standard, New Delhi-2004.IS 516-1959 (Reaffirmed 2004): Methods of tests for strength of concrete, Bureau of Indian Standard, New Delhi-2004. 